\title{
Preliminary evidence using negative pressure wound therapy to achieve limb salvage for the ischemic diabetic foot
}

\author{
Joe Chi-Cheng Fang', Yu-Tsung Chen ${ }^{2,3}$, Yin-Shuo Chang ${ }^{4}$, Jen-Hsiang Shen ${ }^{5}$, Min-Ling Chen ${ }^{6}$, Chang-Cheng Chang ${ }^{7,8}$ \\ ${ }^{I}$ School of Medicine, University of Queensland, Queensland 4072, Australia. \\ ${ }^{2}$ Department of Dermatology, Shuang Ho Hospital, Taipei Medical University, Taipei 235, Taipei, China. \\ ${ }^{3}$ School of Public Health, College of Public Health and Nutrition, Taipei Medical University, Taipei 110, Taipei, China. \\ ${ }^{4}$ Department of Dermatology, Taipei Medical University Hospital, Taipei 110, Taipei, China. \\ ${ }^{5}$ Department of Ophthalmology, Linkou Chang Gung Memorial Hospital, Taoyuan 333, Taipei, China. \\ ${ }^{6}$ Aesthetic Medicine Center, Department of Plastic Surgery, Chiayi Chang Gung Memorial Hospital, Puzi City, Chiayi 613, Taipei, China. \\ ${ }^{7}$ Department of Plastic Surgery, Chiayi Chang Gung Memorial Hospital, Puzi City, Chiayi 613, Taipei, China. \\ ${ }^{8}$ School of Medicine, China Medical University, Taichung 404, Taipei, China.
}

Correspondence to: Prof. Chang-Cheng Chang, Department of Plastic Surgery, Chiayi Chang Gung Memorial Hospital, Puzi City, Chiayi 613, Taipei, China. E-mail: changcc1975@gmail.com

How to cite this article: Fang JCC, Chen YT, Chang YS, Shen JH, Chen ML, Chang CC. Preliminary evidence using negative pressure wound therapy to achieve limb salvage for the ischemic diabetic foot. Plast Aesthet Res 2016;3:378-83.

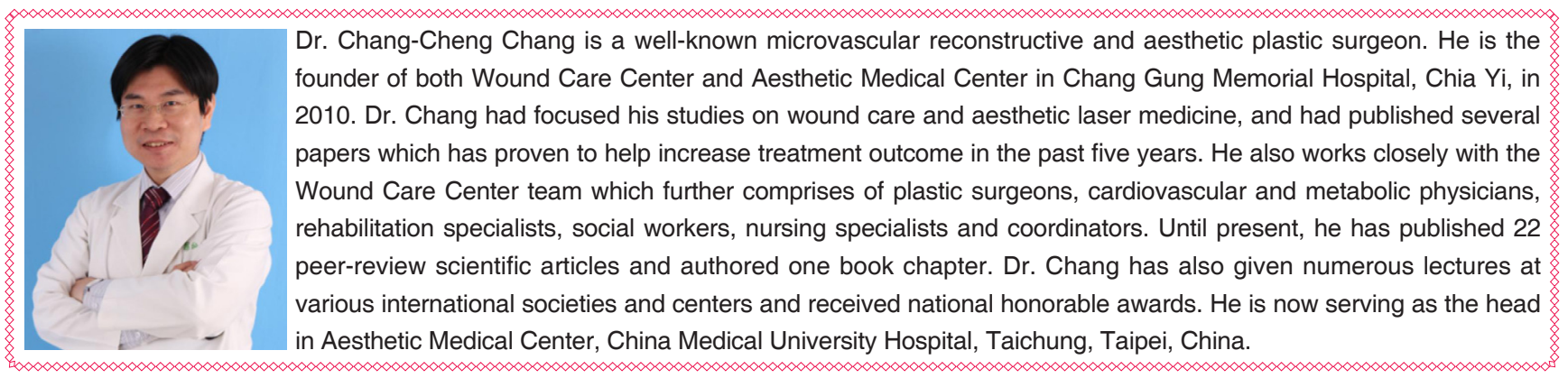

Article history:

Received: 22-02-2016

Accepted: 09-08-2016

Published: 20-12-2016

Key words:

Negative pressure wound therapy, diabetic foot ulcer,

\section{ABSTRACT}

Aim: Negative pressure wound therapy (NPWT) in diabetic foot ulcers (DFU) has been discussed in several studies, but without a focus on peripheral arterial disease (PAD), which is a common comorbidity. This study aims to investigate the feasibility of NPWT in the treatment of DFU with PAD in regards to limb salvage and the clinical course. Methods: The authors retrospectively collected patients with DFU and PAD diagnosed with either Doppler ultrasound or angiography as the PAD study group. Patients with DFU but no PAD were enrolled as the non-PAD comparison group. NPWT was applied to both PAD and non-PAD subjects. Results: There were 10 patients in the PAD group and 3 patients in the non-PAD group. In the PAD

cc) (1) $\$($ ) This is an open access article distributed under the terms of the Creative Commons AttributioncC) Non No SA Nomercial-ShareAlike 3.0 License, which allows others to remix, tweak, and build upon the work non-commercially, as long as the author is credited and the new creations are licensed under the identical terms.

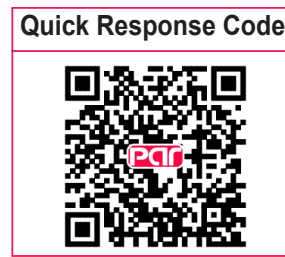


peripheral arterial disease,

limb salvage group, there was a $70 \%$ limb salvage rate with $14.70( \pm 10.33)$ treatment days. The non-PAD comparison group had a higher limb salvage rate (100\% vs. $70 \%$, respectively), but a longer treatment time (30.00 vs. 14.70 days, $P<0.05$, respectively) when compared to the PAD group. The 3 patients in the PAD group who failed limb salvage all had issues related to uncontrolled infection. Conclusion: NPWT is a feasible adjuvant therapy for DFU in patients with PAD, with a $70 \%$ limb salvage rate. Prolonged treatment time was due to the initial severity of the subjects with multiple comorbidities. The main reason for limb loss was intractable infection.

\section{INTRODUCTION}

Negative pressure wound therapy (NPWT) has gained significant interest in the treatment of complex wounds and decreasing wound healing time..$^{[1-5]}$ Previous studies have suggested that NPWT maximizes blood flow and promotes granulation tissue formation ${ }^{[6]}$ at an intermittent setting of $-125 \mathrm{mmHg}^{[7]}$ Other research has also claimed benefits such as oedema reduction, ${ }^{[8,9]}$ an enhanced wound healing microenvironment, improved immunologic response, ${ }^{[10,11]}$ bacterial clearance, ${ }^{[8]}$ and higher flap survival rate. ${ }^{[8,12]}$ NPWT was originally developed as a treatment for decubitus ulcers and wounds with vascular dysfunction, ${ }^{[13]}$ but its application has now been diversified to acute complex wounds. ${ }^{[14]}$ However, there are still few articles that discuss the application of NPWT for the treatment of diabetic foot ulcers (DFU) and its potential for limb salvage.

There is a $10-25 \%$ risk in diabetics of developing a foot ulcer, ${ }^{[15]}$ and foot ulcers make up $84 \%$ of all nontraumatic amputations. ${ }^{[15]}$ Furthermore, patients with diabetic foot amputation have a five year mortality rate as high as $55 \% .{ }^{[16,17]}$ In addition, $39 \%$ of diabetic patients present with peripheral arterial occlusive disease, ${ }^{[18]}$ and $46 \%$ of these patients will sustain a limb amputation. ${ }^{[19]}$ Of the few studies on the benefits of NPWT in the diabetic foot over the last ten years,${ }^{[1,20]}$ the focus on the use of NPWT to achieve limb salvage in patients with DFU and peripheral arterial disease (PAD) is even rarer. Armstrong et al. ${ }^{[1]}$ in 2005 suggested an increase in the rate of wound healing and granulation tissue formation in patients with DFU and partial amputation, and Nather et al ${ }^{[20]}$ in 2010 suggested the use of NPWT in preparation for split-skin graft. However, neither study addressed the presence of PAD. Thus, this study aims to investigate the feasibility of the use of NPWT in the treatment of the diabetic foot ulcer in patient with PAD in regards to limb salvage and clinical course.

\section{METHODS}

A retrospective study of patients with DFU was collected following approval by the Institutional Review Board of Chang Gung Memorial Hospital (number 101-3407B). Case inclusion criteria included age above 18 years and the presence of type 2 diabetes mellitus. PAD was diagnosed with either Doppler ultrasound or angiography in the PAD study group. Patients with DFU but not PAD as documented by Duplex sonography or angiography were enrolled as a comparison non-PAD group $(n=3)$. Exclusion criteria included superficial wound (e.g. Wagner Grade I), burn wounds, malignant disease, collagen vascular disease, and venous insufficiency.

Patient information collected included gender, age, comorbidities, whether or not percutaneous transluminal angiography (PTA) had been performed, admission duration, diabetes diagnosis year (DDY), wound location, wound size, wound culture, University of Texas grading, Wagner grading, DFU score (DFUS), number of NPWT applications, application duration, and if the affected limb(s) had been amputated after at least 6 -months of follow up. Wound size was recorded as width $\times$ length $(\mathrm{cm} \times \mathrm{cm})$. DFU score assessment was followed by the guidelines established by Beckert et al. ${ }^{[21]}$ of examining for a palpable pedal pulse, probing to bone, ulcer location, and presence of multiple ulcerations. Patients were negatively selected in that only subjects who were unlikely to benefit from standard moist wound therapy, as determined by depth of the wound, were enrolled in this study. Comorbidities that were recorded include the presence of end-stage renal disease, coronary artery disease, hypertension, and cerebrovascular accidents. Treatment days were determined by the days with NPWT application. Limb salvage was determined by successful wound closure or limb preservation throughout the study for a minimum of 6 months follow-up.

\section{Procedure}

Initial treatment for the diabetic foot in both PAD and non-PAD subjects involved surgical debridement of infected and non-viable tissue around the wound until healthy tissue was exposed. Wound width and length were measured with a ruler and photos were taken with a digital camera after debridement and throughout the treatment [Figure 1]. NPWT was performed with devices from different companies (Kinetic Concepts Inc., San Antonio, Texas, or RENASYSTM, or Smith and Nephew, Hull, UK). Application of NPWT devices began with modification of the sterile polyurethane 

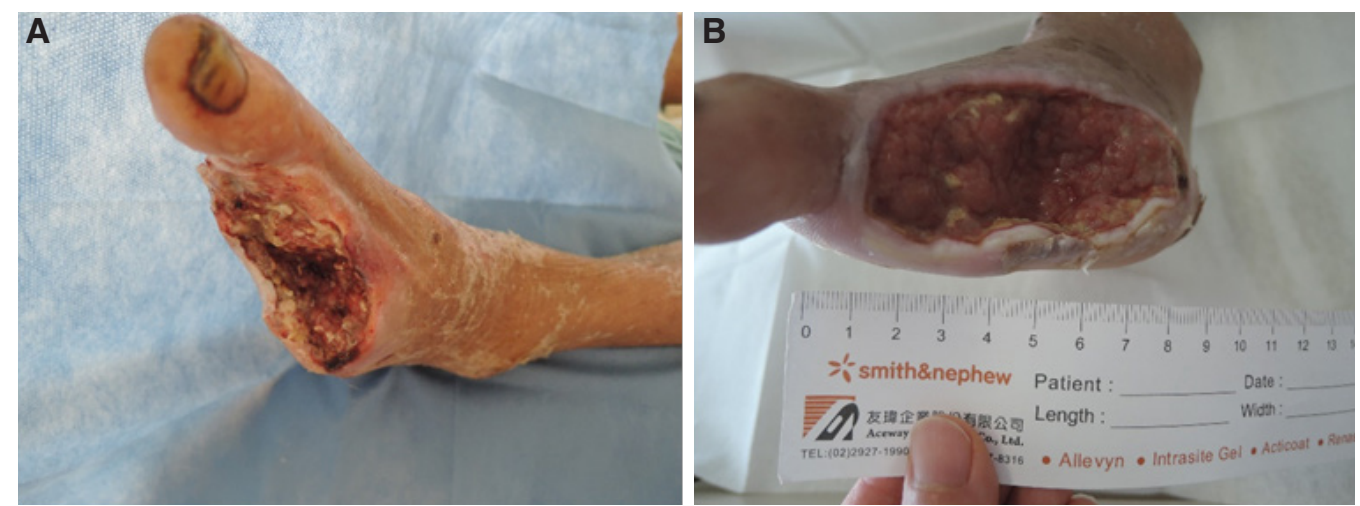

Figure 1: Healing progress of a patient with a dorsal foot ulcer after 9 treatment days of NPWT. A: patient's wound from a diabetic foot ulcer after debridement and partial foot amputation before NPWT; B: increasing granulation observable after NPWT. NPWT: negative pressure wound therapy

sponge dressing to fit the ulcer. The procedure for NPWT device installation followed the manufacture's manual, with pressure which was maintained between -100 and $-125 \mathrm{mmHg}$ with the intermittent mode setting.

Sponge dressing were changed every $72 \mathrm{~h}$ to allow wound cleansing with sterile saline. Infection control was maintained by the application of antibiotics and debridement if necessary. Wound size was also measured and photographed [Figure 1]. The NPWT device was terminated if any adverse effects, such as ongoing infection or intolerable pain, were observed. NPWT was completed once the wound had closed and patient was discharged.

\section{Statistical analysis}

The Mann-Whitney $U$ test was performed for continuous variables using SPSS Statistics (version 19). A $P$ value $<0.05$ was considered to be statistically significant. The power of the study was determined to be $77.6 \%$.

\section{RESULTS}

Between October 2010 and June 2015, a total of 13 patients' data were collected. Ten patients with PAD were enrolled in the study group, and 3 patients without PAD were enrolled as a comparison group. The subjects' basic information, wound character, grading, NPWT application, and outcome are presented [Table 1].

Subjects in the PAD study group were between the ages of 36-73 years old, with a mean age of 58.40 $( \pm 10.18)$ years. Hospital admission duration ranged from 27-103 days, with a mean of 64.44 ( \pm 22.10 ) days [Table 2]. Many subjects in the study group had additional comorbidities, including end-stage renal disease $(n=5)$, coronary arterial disease $(n=3)$, hypertension $(n=7)$, and a history of cerebrovascular accidents $(n=2)$. Eight of the 10 PAD subjects underwent successful PTA. DDY across subjects ranged from 8-23 years, with a mean of 14.20 $( \pm 5.67)$ years [Table 2]. The most common location of the wound was on the dorsal foot $(n=6)$, followed by the plantar surface $(n=3)$. The diabetic foot wound size averaged $71.83( \pm 93.44) \mathrm{cm}^{2}$ and ranged 2.25$300 \mathrm{~cm}^{2}$ [Table 2]. The DFUS ranged from 1-4, with a mean of $2.60( \pm 0.67)$ [Table 2]. There was only 1 subject with grade D2 and 9 subjects with grade D3 in the University of Texas grading system. There was 1 subject with grade II, 5 subjects with grade III, and 4 subjects with grade IV in Wagner's DM foot grading [Table 2]. The number of NPWT treatments ranged from $1-13$, with a mean of $4.90( \pm 3.44)$ treatments. Treatment days ranged from 3-39 days with a mean of 14.70 ( \pm 10.33 ) days. The limb salvage rate was $70 \%$ in the study group. There were three complications, all of which were due to uncontrolled infections, resulting in 1 mortality, 1 amputation, and 1 transferral to another center.

Three non-PAD subjects had grade III (1 subject) and grade IV (2 subjects) scores by Wagner's grading scale. When comparing the PAD and non-PAD subjects, their age, DDY, and hospital admission rates were similar ( 58.4 vs. 58.3 years old; 14.2 vs. 15.3 years; 64.44 vs. 60 days). The wound area was larger and DFUS were higher in PAD subjects than in non-PAD subjects $\left(71.83\right.$ vs. $50.83 \mathrm{~cm}^{2} ; 2.6$ vs. 2). However, the number of NPWT application was significantly lower in PAD subjects than in nonPAD subjects $(P<0.05)$. The number of treatment days were correspondingly significantly fewer in PAD subjects $(P<0.05)$ [Table 2]. All 3 complications were in the PAD study group. The non-PAD comparison group had a $100 \%$ limb salvage rate. Two non-PAD subjects continued NPWT after the study due to failure of wound closure, but their status had improved at 6-month follow-up. No known adverse events related to NPWT were observed in both groups. In the PAD group, there were no significant differences in clinical 
Table 1: Patient characteristics of PAD group (No. 1-10) and non-PAD comparison group (No. 11-13)

\begin{tabular}{|c|c|c|c|c|c|c|c|c|c|c|c|c|}
\hline $\begin{array}{l}\text { No. of } \\
\text { subject }\end{array}$ & $\begin{array}{c}\text { Age } \\
\text { (years) }\end{array}$ & Gender & $\begin{array}{l}\text { Admission } \\
\text { length (days) }\end{array}$ & Comorbidities & DDY & $\begin{array}{l}\text { Wound size } \\
\left(\mathrm{cm}^{3} / \mathrm{cm}^{2}\right)\end{array}$ & $\begin{array}{c}\text { Wound } \\
\text { location }\end{array}$ & $\begin{array}{l}\text { No. of VAC } \\
\text { application }\end{array}$ & $\begin{array}{l}\text { Treatment } \\
\text { time }\end{array}$ & $\begin{array}{l}\text { Follow } \\
\text { up (days) }\end{array}$ & DFUS & Result \\
\hline 1 & 36 & Male & 64 & PAD, osteomyelitis & 9 & $12 \times 4 \times 1$ & $\begin{array}{l}\text { Left dorsal } \\
\text { foot }\end{array}$ & 3 & 9 & 57 & 1 & $\begin{array}{l}\text { Spontaneous } \\
\text { closure }\end{array}$ \\
\hline 2 & 40 & Male & 63 & $\begin{array}{l}\text { PAD, osteomyelitis, } \\
\text { ESRD, HTN }\end{array}$ & 9 & $7 \times 3$ & Right plantar & 5 & 15 & 114 & 3 & $\begin{array}{l}\text { Spontaneous } \\
\text { closure }\end{array}$ \\
\hline 3 & 64 & Male & 56 & $\begin{array}{c}\text { PAD, osteomyelitis, } \\
\text { HTN, CVA }\end{array}$ & 15 & $15 \times 7$ & $\begin{array}{l}\text { Left dorsal } \\
\text { foot }\end{array}$ & 5 & 15 & 50 & 3 & $\begin{array}{l}\text { Spontaneous } \\
\text { closure }\end{array}$ \\
\hline 4 & 65 & Male & 46 & PAD & 23 & $11 \times 4 \times 3$ & $\begin{array}{l}\text { Left dorsal } \\
\text { foot }\end{array}$ & 6 & 18 & 85 & 2 & $\begin{array}{l}\text { Spontaneous } \\
\text { closure }\end{array}$ \\
\hline 5 & 70 & Male & 45 & $\begin{array}{l}\text { PAD, osteomyelitis, } \\
\text { ESRD, HTN, CAD }\end{array}$ & 8 & $4 \times 7 \times 0.5$ & $\begin{array}{l}\text { Left dorsal } \\
\text { foot }\end{array}$ & 3 & 9 & 122 & 2 & $\begin{array}{l}\text { Spontaneous } \\
\text { closure }\end{array}$ \\
\hline 6 & 50 & Male & 69 & PAD & 20 & $20 \times 15 \times 1$ & Multiple & 6 & 18 & 108 & 4 & $\begin{array}{l}\text { Closure with } \\
\text { skin graft }\end{array}$ \\
\hline 7 & 61 & Male & 27 & $\begin{array}{c}\text { PAD, osteomyelitis, } \\
\text { HTN }\end{array}$ & 10 & $1.5 \times 1.5$ & Left plantar & 1 & 3 & 211 & 2 & Improved \\
\hline 8 & 65 & Male & 39 & $\begin{array}{l}\text { PAD, osteomyelitis, } \\
\text { ESRD, CAD, HTN }\end{array}$ & 10 & $17 \times 7$ & Left plantar & 2 & 6 & 39 & 3 & $\begin{array}{l}\text { Extended } \\
\text { infection }\end{array}$ \\
\hline 9 & 73 & Male & 68 & $\begin{array}{l}\text { PAD, osteomyelitis, } \\
\text { ESRD, CAD, HTN }\end{array}$ & 18 & $6 \times 3$ & Right toe & 5 & 15 & 121 & 3 & Amputation \\
\hline 10 & 60 & Male & 103 & $\begin{array}{l}\text { PAD, osteomyelitis, } \\
\text { ESRD, HTN, CVA }\end{array}$ & 20 & $11 \times 3 \times 2$ & Right heel & 13 & 39 & 20 & 3 & $\begin{array}{l}\text { Expired due } \\
\text { to sepsis }\end{array}$ \\
\hline 11 & 69 & Male & 86 & $\begin{array}{l}\text { Osteomyelitis, } \\
\text { ESRD, HTN, CVA }\end{array}$ & 15 & $5 \times 4$ & Left heel & 7 & 21 & 86 & 2 & $\begin{array}{l}\text { Spontaneous } \\
\text { closure }\end{array}$ \\
\hline 12 & 51 & Male & 94 & Osteomyelitis, HTN & 11 & $11 \times 7.5$ & $\begin{array}{l}\text { Left dorsal } \\
\text { foot }\end{array}$ & 12 & 36 & 384 & 2 & Improved \\
\hline \multirow[t]{2}{*}{13} & 55 & Male & 60 & Osteomyelitis, HTN & 20 & $10 \times 5$ & $\begin{array}{l}\text { Right dorsal } \\
\text { foot }\end{array}$ & 11 & 33 & 388 & 2 & Improved \\
\hline & $\begin{array}{c}58.38 \pm \\
11.42\end{array}$ & & $63.08 \pm 21.78$ & & $\begin{array}{c}14.46 \pm \\
5.25\end{array}$ & & & $6.08 \pm 3.80$ & $\begin{array}{c}18.23 \pm \\
11.39\end{array}$ & $\begin{array}{c}137.31 \pm \\
120.38\end{array}$ & & \\
\hline
\end{tabular}

*Improved is defined as limb salvage within half a year, but has not achieved wound closure. DDY: diabetes diagnosis year; DFUS: diabetic foot ulcer score; PAD: peripheral arterial disease; ESRD: end stage renal disease; HTN: hypertension; CVA: cerebrovascular accident; CAD: coronary arterial disease; OSSA: oxacillin-sensitive staphylococcus aureus; MRSA: methicillin-resistant staphylococcus aureus

Table 2: Subjects with PAD compare with non-PAD in wound characteristic and NPWT application

\begin{tabular}{lccc}
\hline Variable & PAD $(\boldsymbol{n}=\mathbf{1 0})$ & Non-PAD $(\boldsymbol{n}=\mathbf{3})$ & $\boldsymbol{P}$ \\
\hline Age (years) & $58.40 \pm 10.18$ & $58.33 \pm 9.45$ & \\
DDY & $14.20 \pm 5.67$ & $15.33 \pm 4.51$ & \\
Wound area $\left(\mathrm{cm}^{2}\right)$ & $71.83 \pm 93.44$ & $50.83 \pm 31.26$ & \\
Texas grading & $1 \mathrm{D} 2,9 \mathrm{D} 3$ & $1 \mathrm{~B} 2,2 \mathrm{B3}$ & \\
DFUS & $2.60 \pm 0.67$ & $2.00 \pm 0.00$ & \\
No. of NPWT application & $4.90 \pm 3.44$ & $10.00 \pm 2.65$ & $<0.05$ \\
NPWT treatment (days) & $14.70 \pm 10.33$ & $30.00 \pm 7.94$ & $<0.05$ \\
Hospital admission (days) & $64.44 \pm 22.10$ & $60.00 \pm 17.78$ & \\
Limb salvage (\%) & $70 \%{ }^{*}$ & $100 \%$ & \\
\hline
\end{tabular}

*3 infection complications resulting in 1 mortality, 1 amputation, and 1 transfer. Data shown as mean \pm SD. DDY: diabetes diagnosis year; DFUS: diabetic foot ulcer score; PAD: peripheral arterial disease; NPWT: negative pressure wound therapy

features between patients who had limb salvage and those who did not [Table 3].

\section{DISCUSSION}

PAD is a known risk factor for diabetic foot amputation, ${ }^{[22]}$ with a $29 \%$ amputation rate and $55 \%$ 5 -year mortality associated with ischemic DFU. ${ }^{[17]}$ Our studies have also shown that many diabetic patients present with PAD in combination with other comorbidities, including hypertension (70\%) and end stage renal disease $(50 \%)$. Patients with DFU and PAD usually had poor infection control, hence the majority of cases presented with deep infections with
Table 3: Subjects with limb salvaged versus limb loss

\begin{tabular}{lcc}
\hline Variable & Limb salvaged $(\boldsymbol{n}=\mathbf{7})$ & Limb loss $(\boldsymbol{n}=\mathbf{3})$ \\
\hline Age (years) & $55.14 \pm 13.25$ & $66.00 \pm 6.56$ \\
DDY & $13.43 \pm 6.02$ & $16.00 \pm 5.29$ \\
Wound area $\left(\mathrm{cm}^{2}\right)$ & $78.32 \pm 102.92$ & $56.67 \pm 54.50$ \\
Texas grading & $1 \mathrm{D} 2,6 \mathrm{D} 3$ & $3 \mathrm{D} 3$ \\
DFUS & $2.43 \pm 0.98$ & $3.00 \pm 0.00$ \\
Number of NPWT application & $4.14 \pm 1.86$ & $6.67 \pm 5.69$ \\
NPWT treatment (days) & $12.43 \pm 5.59$ & $20.00 \pm 17.06$ \\
Hospital admission (days) & $52.86 \pm 14.58$ & $70.00 \pm 32.05$ \\
\hline
\end{tabular}

Data shown as mean \pm SD. DDY: diabetes diagnosis year; DFUS: diabetic foot ulcer score; NPWT: negative pressure wound therapy

osteomyelitis. Repeated and frequent debridement for infection control created a vicious cycle for these patients, as frequent debridement often led to inevitable limb amputation if there was no strategy for reconstruction due to poor circulation. In this situation, it is reasonable to apply NPWT as an adjuvant therapy to achieve limb salvage. Although there have been few studies on the benefits of NPWT in the treatment of diabetic foot ulcers in the last 10 years, ${ }^{[1,20]}$ this is the first study to focus on limb salvage following NPWT in patients with diabetic foot ulcers and PAD. The current study shows a $70 \%$ limb salvage rate in a group of patients with higher wound severity.

Previous studies have demonstrated that NPWT may facilitate wound healing through extracellular, cellular and complex effects via increased blood 
flow, reduced edema, promoted granulation tissue formation, decreased number of microorganisms, and fewer endotoxins. ${ }^{[6-10]}$ NPWT increases blood flow through increased blood volume, velocity and vascular diameter, ${ }^{[6]}$ which may help to restore arterial insufficiency in patients with PAD. Further actions on angiogenesis and endothelial proliferation ${ }^{[6]}$ may result in shortening of wound healing time in subjects with DFU and PAD. Although the gold standard treatments for PAD are angioplasty and surgery to fully restore blood flow, NPWT may also play a role in the wound healing process in patients with DFU and PAD by helping to achieve limb salvage. The length of treatment was not solely determined by the severity of vasculopathy. Both infection and associated comorbidities could prolong the hospitalization as observed in non-PAD subjects in the current study.

Other studies regarding limb salvage treatment for DFU regard use of free flap surgery. Although free flaps have the advantage of covering a larger wound area as compared to NPWT, there are still some drawbacks. Aside from donor side morbidity and prolonged operation time, these patients usually present with other comorbidities and a lack of recipient vessels. Also, the free flap may not always completely fill the wound, leaving a dead space and undermining, which can in turn lead to recurrence or wound dehiscence. Kallio et al. ${ }^{[23]}$ reported in their 2015 study that free flaps required a treatment time of 9 to 20 months, in correlation to the degree of PAD. They also identified a limb amputation rate of $30 \%$ for a correctable ischemic artery, and $50 \%$ for an uncorrectable ischemic artery in DFU patients with PAD, suggesting that flap use is less desirable in patients with severe PAD. The limb salvage rate for DFU with the use of NPWT ranges from $97-100 \%$ in previous studies. ${ }^{[1,20]}$ On the other hand, the free flap salvage rate range is $76-91 \% .{ }^{[23-25]}$ Further comparative case control studies between NPWT and free flaps would be useful in highlighting the advantages of each.

NPWT also had some limitations. Coverage of wounds with the NPWT sponge makes wound observation and infection detection difficult. Although Banwell et al. ${ }^{[10]}$ suggested that NTWT may provide better bacterial clearance, Mouës et al. ${ }^{[26]}$ and Weed et al. ${ }^{[27]}$ have shown a constant bacterial concentration. In the current study, there were 3 complications consisting of 1 mortality due to sepsis and 2 uncontrolled infections with 1 resulting in limb amputation. Because all 3 failed cases had previously undergone PTA, the lack of circulation was unlikely to have been the only determining factor for limb salvage. Hence, this study stresses the importance of infection control as a determining factor for the success of NPWT.

In addition to observational studies, long-term data from three non-PAD subjects allows comparison between subjects with and without PAD. The limb salvage rate was as expected lower in PAD than non-PAD subjects. However, in the current study, the mean number of NPWT treatment days was 14.7 in the PAD group, as compared to 30 days in the non-PAD group, which may be related to the lower number of NPWT applications in the PAD group than in the non-PAD group. The prolonged treatment days in the non-PAD subjects may be attributed to their stagnant improvement. Since there are additional determinants, it cannot be concluded that PAD is the sole cause for this unexpected result. These determinants include other comorbidities such as end stage renal disease, hypertension, stroke, and osteomyelitis, all of which were present in one of the non-PAD subjects. The number of lengthened treatment days may have been due to severe osteomyelitis, since most enrolled non-PAD subjects typically had an infection of which the severity rendered standardized moist wound therapy ineffective.

As this study is preliminary with a limited number of subjects in the non-PAD group, further studies with more subjects and higher power are urgently needed to determine significance. Future studies may also include qualitative data including $\mathrm{HbA} 1 \mathrm{c}$, kidney function, hepatic function, hemoglobin, C-reactive protein, and current medications.

In conclusion, patients with DFU and PAD possess many additional comorbidities which limit their options for reconstruction following repeated debridement. NPWT remains an effective method of treatment for DFU with PAD with a high percentage of limb salvage. The limb salvage rate was not as high as in prior studies of NPWT as their subjects were not exclusively patients with DFU and PAD. The main reason for limb loss was intractable infection.

\section{Financial support and sponsorship} None.

\section{Conflicts of interest}

There are no conflicts of interest.

\section{Patient consent}

All patients gave informed consent prior to treatment.

\section{Ethics approval}

The study was approved by the Institutional Review 


\section{Board of Chang Gung Memorial Hospital (number 101-3407B).}

\section{REFERENCES}

1. Armstrong DG, Lavery LA; Diabetic Foot Study Consortium. Negative pressure wound therapy after partial diabetic foot amputation: a multicentre, randomised controlled trial. Lancet 2005;366:1704-10.

2. Eginton MT, Brown KR, Seabrook GR, Towne JB, Cambria RA. A prospective randomized evaluation of negative-pressure wound dressings for diabetic foot wounds. Ann Vasc Surg 2003;17:645-9.

3. Lavery LA, Boulton AJ, Niezgoda JA, Sheehan P. A comparison of diabetic foot ulcer outcomes using negative pressure wound therapy versus historical standard of care. Int Wound $J$ 2007;4:103-13.

4. Zgonis T, Roukis TS. A systematic approach to diabetic foot infections. Adv Ther 2005;22:244-62.

5. Kloth LC. 5 questions-and answers-about negative pressure wound therapy. Adv Skin Wound Care 2002;15:226-9.

6. Schintler M. Negative pressure therapy: theory and practice. Diabetes Metab Res Rev 2012;28 Suppl 1:72-7.

7. Morykwas MJ, Faler BJ, Pearce DJ, Argenta LC. Effects of varying levels of subatmospheric pressure on the rate of granulation tissue formation in experimental wounds in swine. Ann Plast Surg 2001;47:547-51.

8. Morykwas MJ, Argenta LC, Shelton-Brown EI, McGuirt W. Vacuumassisted closure: a new method for wound control and treatment: animal studies and basic foundation. Ann Plast Surg 1997;38:553-62.

9. Morykwas MJ, Simpson J, Punger K, Argenta A, Kremers L, Argenta J. Vacuum-assisted closure: state of basic research and physiologic foundation. Plast Reconstr Surg 2006;117:S121-6.

10. Banwell PE, Musgrave M. Topical negative pressure therapy: mechanisms and indications. Int Wound J 2004;1:95-106.

11. Hunter JE, Teot L, Horch R, Banwell PE. Evidence-based medicine: vacuum-assisted closure in wound care management. Int Wound $J$ 2007;4:256-69.

12. Webster J, Scuffham P, Stankiewicz M, Chaboyer WP. Negative pressure wound therapy for skin grafts and surgical wounds healing by primary intention. Cochrane Database Syst Rev 2014;(10):CD009261.

13. Wongworawat MD, Schnall SB, Holtom PD, Moon C, Schiller F. Negative pressure dressing as an alternative technique for the treatment of infected wounds. Clin Orthop Relat Res 2003;(414):45-8.
14. Hunter S, Langemo D, Hanson D, Anderson J, Thomson P. The use of negative pressure wound therapy. Adv Skin Wound Care 2007;20:90-5.

15. Brem H, Sheehan P, Rosenberg HJ, Schneider JS, Boulton AJ. Evidence-based protocol for diabetic foot ulcers. Plast Reconstr Surg 2006;117:S193-209; discussion S210-1.

16. Herman W. The evidence base for diabetes care. 2nd ed. Chichester, West Sussex, UK: Wiley-Blackwell; 2010. p. 403-17.

17. Moulik P, Mtonga R, Gill G. Amputation and mortality in new-onset diabetic foot ulcers stratified by etiology. Diabetic Care 2003;26:491-4.

18. Mwebaze RM, Kibirige D. Peripheral arterial disease among adult diabetic patients attending a large outpatient diabetic clinic at a national referral hospital in Uganda: a descriptive cross sectional study. PLoS One 2014;9:e10521.

19. Pecoraro RE, Reiber GE, Burgess EM. Pathways to diabetic limb amputation. Basis for prevention. Diabetes Care 1990;13:513-21.

20. Nather A, Chionh SB, Han AY, Chan PP, Nambiar A. Effectiveness of vacuum-assisted closure (VAC) therapy in the healing of chronic diabetic foot ulcers. Ann Acad Med Singapore 2010;39:353-8.

21. Beckert S, Witte M, Wicke C, Konigsrainer A, Coerper S. A new wound-based severity score for diabetic foot ulcers: a prospective analysis of 1,000 patients. Diabetic Care 2006;29:988-92.

22. Pemayun TG, Naibaho RM, Novitasari D, Amin N, Minuljo TT. Risk factors for lower extremity amputation in patients with diabetic foot ulcers: a hospital based case-control study. Diabet Foot Ankle 2015;6:29629.

23. Kallio M, Vikatmaa P, Kantonen I, Lepantalo M, Venermo M, Tukiainen E. Strategies for free flap transfer and revascularization with long-term outcome iin the treatment of large diabetic foot lesions. Eur J Vasc Endovasc Surg 2015;50:223-30.

24. Oh TS, Lee HS, Hong JP. Diabetic foot reconstruction using free flaps increases 5-year-survival rate. J Plast Reconstr Aesthet Surg 2013;66:243-50

25. Schirmer S, Ritter RG, Fansa H. Vascular surgery, microsurgery and supramicrosurgery for treatment of chronic diabetic foot ulcers to prevent amputations. PLoS One 2013;8:e74704.

26. Mouës CM, Vos MC, van den Bemd GJ, Stijnen T, Hovius SE. Bacterial load in relation to vacuum-assisted closure wound therapy: a prospective randomized trial. Wound Repair Reg 2004;12:11-7.

27. Weed T, Ratliff C, Drake DB. Quantifying bacterial bioburden during negative pressure wound therapy: does the wound VAC enhance bacterial clearance? Ann Plast Surg 2004;52:276-9; discussion 279-80. 